Check for

tostates

Cite as

Nano-Micro Lett.

(2020) 12:48

Received: 27 November 2019

Accepted: 12 January 2020

Published online: 12 February 2020

(C) The Author(s) 2020

\section{Stabilising Cobalt Sulphide Nanocapsules with Nitrogen-Doped Carbon for High-Performance Sodium-Ion Storage}

\author{
Yilan $\mathrm{Wu}^{1}$, Rohit R. Gaddam ${ }^{1}$, Chao Zhang ${ }^{2}$, Hao Lu${ }^{1}$, Chao Wang ${ }^{3}$, Dmitri Golberg ${ }^{2}$, \\ Xiu Song Zhao ${ }^{1,3} \bowtie$ \\ Yilan Wu and Rohit R. Gaddam contributed equally to this work. \\ $\bowtie$ Xiu Song Zhao, george.zhao@uq.edu.au \\ 1 School of Chemical Engineering, The University of Queensland, St Lucia, Brisbane, QLD 4072, Australia \\ 2 School of Chemistry, Physics and Mechanical Engineering, Science and Engineering Faculty, Queensland \\ University of Technology, Brisbane, QLD 4001, Australia \\ 3 Institute of Materials for Energy and Environment, College of Materials Science and Engineering, Qingdao \\ University, 308 Ningxia Road, Qingdao 266071, People's Republic of China
}

\title{
HIGHLIGHTS
}

- Cobalt sulphide nanoparticles are encapsulated in nitrogen-rich carbon cages via a simple and scalable method.

- Insight into sodium storage mechanism is systematically studied via in situ TEM and XRD techniques.

- The sodium-ion capacitor device achieved high energy densities of 101.4 and $45.8 \mathrm{Wh} \mathrm{kg}^{-1}$ at power densities of 200 and $10,000 \mathrm{~W} \mathrm{~kg}-1$, respectively, holding promise for practical applications.

ABSTRACT Conversion-type anode materials with a high charge storage capability generally suffer from large volume expansion, poor electron conductivity, and sluggish metal ion transport kinetics. The electrode material described in this paper, namely cobalt sulphide nanoparticles encapsulated in carbon cages $\left(\mathrm{Co}_{9} \mathrm{~S}_{8} @ \mathrm{NC}\right)$, can circumvent these problems. This electrode material exhibited a reversible sodium-ion storage capacity of $705 \mathrm{mAh} \mathrm{g}^{-1}$ at $100 \mathrm{~mA} \mathrm{~g}^{-1}$ with an extraordinary rate capability and good cycling stability. Mechanistic study using the in situ transmission electron microscope technique revealed that
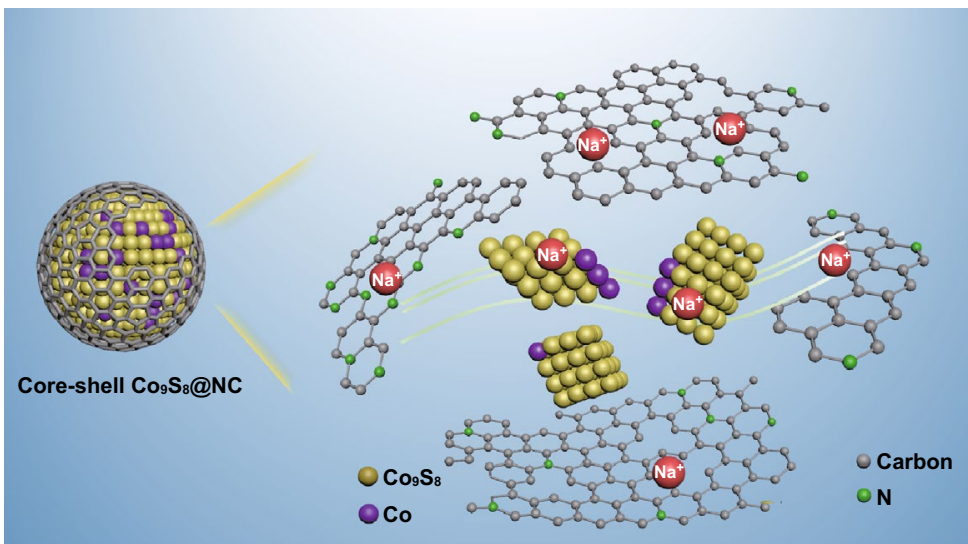
the volumetric expansion of the $\mathrm{Co}_{9} \mathrm{~S}_{8}$ nanoparticles is buffered by the carbon cages, enabling a stable electrode-electrolyte interface. In addition, the carbon shell with high-content doped nitrogen significantly enhances the electron conductivity of the $\mathrm{Co}_{9} \mathrm{~S}_{8} @ \mathrm{NC}$ electrode material and provides doping-induced active sites to accommodate sodium ions. By integrating the $\mathrm{Co}_{9} \mathrm{~S}_{8} @ \mathrm{NC}$ as negative electrode with a cellulose-derived porous hard carbon/graphene oxide composite as positive electrode and $1 \mathrm{M} \mathrm{NaPF}_{6}$ in diglyme as the electrolyte, the sodium-ion capacitor full cell can achieve energy densities of 101.4 and $45.8 \mathrm{Wh} \mathrm{kg}^{-1}$ at power densities of 200 and $10,000 \mathrm{~W} \mathrm{~kg}^{-1}$, respectively.

KEYWORDS Cobalt sulphide; Nitrogen-doped carbon; Core-shell structure; Sodium-ion capacitors 


\section{Introduction}

Sodium-ion batteries (NIBs) have resurfaced as the most promising energy storage technology for large-scale energy storage applications. With a wide spectrum of cathode materials suitable for NIBs, it has been of a great challenge for anode materials to compete with the current lithium-ion battery technology. Transition metal chalcogenides (TMCs) with high charge storage capacity, suitable redox voltage, and good electron conductivity have advantages compared to their oxide counterparts [1-3]. Among various TMCs, cobalt sulphides hold a great potential as anode materials for highperformance NIBs due to their high theoretical capacities, relatively low voltage plateau, and low cost [4-6]. Unfortunately, this family of materials suffers from sluggish kinetics of sodium-ion transport and large volume changes during charge/discharge, causing problems such as severe pulverisation and unstable solid electrolyte interphase (SEI) films [7].

Strategies have been proposed to address the above issues, including optimisation of electrode materials [8]. Nanoparticles (NPs) have been shown to not only improve the reaction kinetics due to shortened charge transport pathway but also effectively relieve mechanical strain induced by volume expansion [9]. However, NPs tend to aggregate during charge/discharge, leading to rapid loss in electroactivity. Dispersing NPs on carbon substrates has been shown to be a good solution to solving the particle aggregation problem [10]. Here we demonstrate a strategy for stabilising NPs by encapsulating them in carbon cages. Effective confinement from carbon shells not only eases the self-aggregation and pulverisation but also buffers the volumetric expansion and ensures a stable SEI film during sodiation/desodiation [11, 12]. Moreover, the enhanced contact between carbon layer and active components in the core-shell structure provides sufficient channels for fast electron/ion transport, thereby increasing the electronic conductivity and charge storage kinetics of the composite [13]. On the other hand, doping of carbon materials with heteroatoms such as nitrogen, sulphur, phosphorous, or boron can improve ionic and electronic conductivity [14-16]. Also, doping-induced defects on carbon could create localised active sites to accommodate sodium ions and favour ion transfer, giving rise to higher sodium storage performance $[17,18]$.

In this work, nitrogen-doped carbon frame was used to stabilise $\mathrm{Co}_{9} \mathrm{~S}_{8}$ nanocapsules. The obtained electrode material (hereafter designated as $\mathrm{Co}_{9} \mathrm{~S}_{8} @ \mathrm{NC}$ ) was used as anode for sodium-ion storage. It delivered a specific capacity as high as $705 \mathrm{mAh} \mathrm{g}^{-1}$ at $100 \mathrm{~mA} \mathrm{~g}^{-1}$ and exhibited an excellent rate performance $\left(613 \mathrm{mAh} \mathrm{g}^{-1}\right.$ at $\left.4000 \mathrm{~mA} \mathrm{~g}^{-1}\right)$, which is among the highest in all reported $\mathrm{Co}_{9} \mathrm{~S}_{8}$ electrodes for NIBs [4, 5, 19-22]. Insight into sodium storage mechanism in $\mathrm{Co}_{9} \mathrm{~S}_{8} @ \mathrm{NC}$ is systematically studied and discussed via multiple analytical methods. The synthetic method is very versatile and can be easily extended to fabricate other TMC-based composites for energy storage.

\section{Experimental Section}

\subsection{Synthesis of $\mathrm{Co}_{9} \mathrm{~S}_{8} @ \mathrm{NC}$ Composites}

The $\mathrm{Co}_{9} \mathrm{~S}_{8} @ \mathrm{NC}$ nanocapsules were synthesised via a facile and scalable one-pot route. Typically, a certain amount of hydrate cobalt sulphate $\left(\mathrm{CoSO}_{4} \cdot 7 \mathrm{H}_{2} \mathrm{O}\right)$ and $20 \mathrm{~g}$ melamine were dissolved in $20 \mathrm{~mL}$ deionised water with ultrasonication and stirring to obtain a pink suspension at room temperature. The suspension was centrifuged and collected, followed by being freeze-dried for $48 \mathrm{~h}$. The resulting violet powder was annealed in a tube furnace at a rate of $5{ }^{\circ} \mathrm{C} \min ^{-1}$ to $750{ }^{\circ} \mathrm{C}$ and kept for $2 \mathrm{~h}$ under the nitrogen atmosphere to obtain the $\mathrm{Co}_{9} \mathrm{~S}_{8} @ \mathrm{NC}$ samples. Melamine was carbonised to form a carbon shell wrapping the $\mathrm{Co}_{9} \mathrm{~S}_{8}$ nanocapsules. By varying the mass ratio of melamine/cobalt sulphate to be 40:6, 40:9, and 40:12, three samples denoted as $\mathrm{Co}_{9} \mathrm{~S}_{8} @ \mathrm{NC}-6, \mathrm{Co}_{9} \mathrm{~S}_{8} @ \mathrm{NC}-9$, and $\mathrm{Co}_{9} \mathrm{~S}_{8} @ \mathrm{NC}-12$ were obtained. Because melamine contains rich nitrogen, high-content doping of nitrogen in the carbon shell occurred. For comparison, $\mathrm{Co}_{9} \mathrm{~S}_{8}$ nanoparticles without carbon shell $\left(\mathrm{Co}_{9} \mathrm{~S}_{8}\right.$-NPs) were also prepared.

\subsection{Synthesis of $\mathrm{Co}_{9} \mathrm{~S}_{8}$ Nanoparticles}

As a reference, $\mathrm{Co}_{9} \mathrm{~S}_{8}$ nanoparticles were also prepared by a modified method as previously reported [23]. Typically, $5 \mathrm{mmol} \mathrm{CoSO}_{4} \cdot 7 \mathrm{H}_{2} \mathrm{O}$ and $5 \mathrm{mmol}$ thiourea were dissolved in ethylene glycol $(30 \mathrm{~mL})$. The obtained solution was placed in a Teflon-lined stainless-steel autoclave and maintained at $160^{\circ} \mathrm{C}$ for $12 \mathrm{~h}$. After cooling down to the room temperature, the precipitates were collected and freeze-dried for $48 \mathrm{~h}$, then followed by the same annealing treatment as the $\mathrm{Co}_{9} \mathrm{~S}_{8} @ \mathrm{NC}$ composites. 


\subsection{Preparation of Cellulose-Derived Porous Carbon/ Graphene Oxide Composite}

Graphite oxide (GO) was prepared using the modified Hummers' method [24, 25]. The resulting GO was dissolved in deionised (DI) water to form GO suspension $\left(2 \mathrm{mg} \mathrm{mL}^{-1}\right)$ by ultrasonication in ice bath for $1 \mathrm{~h}$. Then $0.5 \mathrm{~g}$ MC powder and $1.5 \mathrm{~g}$ zinc chloride $\left(\mathrm{ZnCl}_{2}\right)$ were added into $25 \mathrm{~mL} \mathrm{GO}$ suspension with stirring for $1 \mathrm{~h}$. Afterwards, the mixture was freeze-dried for $24 \mathrm{~h}$, followed by annealing treatment at $550{ }^{\circ} \mathrm{C}$ for $2 \mathrm{~h}$ under nitrogen flow at a heating rate of $5{ }^{\circ} \mathrm{C} \mathrm{min}^{-1}$. The obtained sample was washed with hydrogen chloride solution and DI water to remove residuals. After drying at $60{ }^{\circ} \mathrm{C}$ for $48 \mathrm{~h}$, the cellulose-derived porous carbon/graphene oxide composite was obtained and denoted as CG.

\section{Results and Discussion}

\subsection{Structural and Morphological Characterisation}

The powder diffraction (XRD) patterns of the samples are shown in Fig. 1a. All major diffraction peaks of samples $\mathrm{Co}_{9} \mathrm{~S}_{8} @ \mathrm{NC}-9$ and $\mathrm{Co}_{9} \mathrm{~S}_{8} @ \mathrm{NC}-12$ can be indexed to cubic $\mathrm{Co}_{9} \mathrm{~S}_{8}$ phase (JCPDS No. 04-006-5681) [26], indicating a complete conversion of $\mathrm{CoSO}_{4}$ to $\mathrm{Co}_{9} \mathrm{~S}_{8}$. Also, the $\mathrm{Co}_{9} \mathrm{~S}_{8} @$ NC-6 and $\mathrm{Co}_{9} \mathrm{~S}_{8} @ \mathrm{NC}-9$ sample show peaks at $44.2^{\circ}$ and $51.6^{\circ}$ corresponding to cubic cobalt (JCPDS No. 04-0043107). Previous study has demonstrated that $\mathrm{Co}_{9} \mathrm{~S}_{8}$ could be partially reduced to metallic cobalt through carbothermal reduction during annealing [27]. Therefore, the increase in melamine content in the precursor leads to the formation of higher amount of cobalt in the product.

The survey X-ray photoelectron spectroscopy (XPS) spectrum (Fig. S2) demonstrates the coexistence of Co, $\mathrm{O}, \mathrm{C}, \mathrm{N}$, and $\mathrm{S}$ elements in the $\mathrm{Co}_{9} \mathrm{~S}_{8} @ \mathrm{NC}$ samples. The atomic ratio of each element is listed in Table S1. The XPS spectra of $\mathrm{Co}_{9} \mathrm{~S}_{8} @ \mathrm{NC}-9$ were further analysed. In the Co $2 p_{3 / 2}$ region, the peak located at 780.8 and $778.4 \mathrm{eV}$ can be assigned to $\mathrm{Co}^{2+}$ and $\mathrm{Co}^{3+}$ (Fig. 1b) [28-30]. As shown in Fig. 1c, the characteristic peaks of Co-S located at 162.2 (S $\left.2 p_{3 / 2}\right)$ and $163.4 \mathrm{eV}\left(\mathrm{S} 2 p_{1 / 2}\right)$, further confirming the presence of $\mathrm{Co}_{9} \mathrm{~S}_{8}$. Moreover, binding energies at $168.2\left(\mathrm{~S} 2 p_{3 / 2}\right)$ and $169.4 \mathrm{eV}\left(\mathrm{S} 2 p_{1 / 2}\right)$ correspond to $\mathrm{C}-\mathrm{SO}_{\mathrm{x}}$ groups, which may due to some $\mathrm{SO}_{4}{ }^{2-}$ residue on the sample. The typical high-resolution spectrum of $\mathrm{C} 1 \mathrm{~s}$ in $\mathrm{Co}_{9} \mathrm{~S}_{8} @ \mathrm{NC}$ is presented in Fig. 1d, which reveals the presence of $\mathrm{C}-\mathrm{C}\left(s p^{2}\right), \mathrm{C}-\mathrm{C}$ $\left(s p^{3}\right), \mathrm{C}-\mathrm{N}=\mathrm{C}-\mathrm{O}, \mathrm{C}=\mathrm{O}$, and pi-pi* at binding energies of $284.6,285.2,286.2,287.5$, and $289.5 \mathrm{eV}$, respectively [18]. Also, the pi-pi* bond illustrates the existence of graphitic carbon in the sample. The nitrogen doping into the carbon shell can be verified by the high-resolution $\mathrm{N} 1 \mathrm{~s}$ spectrum shown in Fig. 1e, in which peaks of pyridinic $\mathrm{N}(398.7 \mathrm{eV})$ and pyrrolic $\mathrm{N}(400.9 \mathrm{eV})$ can be observed [31, 32]. The elemental content of nitrogen species on carbon is as high as $13.3 \%$ in the $\mathrm{Co}_{9} \mathrm{~S}_{8} @ \mathrm{NC}-9$ sample. Large quantities of extrinsic defects can be introduced into carbon framework by pyridinic/pyrrolic nitrogen doping, hence favours ion transfer, and enhances the interaction property with sodium ions [17, 33, 34].

Raman spectra of $\mathrm{Co}_{9} \mathrm{~S}_{8} @ \mathrm{NC}$ samples are presented in Fig. 1f. The D peak $\left(\sim 1360 \mathrm{~cm}^{-1}\right)$ arises from defect-activated in-plane breathing modes, corresponding to $s p^{3}$ carbon bonding. The $\mathrm{G}$ peak $\left(\sim 1580 \mathrm{~cm}^{-1}\right)$ is related to in-plane optical phonon modes and corresponds to $s p^{2}$ carbon bonding. The 2D peak $\left(\sim 2700 \mathrm{~cm}^{-1}\right)$ arises from a two-phonon process that is sensitive to the electronic structure. Raman spectra of the $\mathrm{Co}_{9} \mathrm{~S}_{8} @ \mathrm{NC}$ samples show $I_{\mathrm{D}} / I_{\mathrm{G}}$ values of $\sim 1.0$, indicating a high degree of defects due to nitrogen doping $[16,35]$. In addition, for the $\mathrm{Co}_{9} \mathrm{~S}_{8} @ \mathrm{NC}-9$ and $\mathrm{Co}_{9} \mathrm{~S}_{8} @$ $\mathrm{NC}-12$ samples, the Raman bands below $750 \mathrm{~cm}^{-1}$ are well index to $\mathrm{Co}_{9} \mathrm{~S}_{8}$ [23]. While in the $\mathrm{Co}_{9} \mathrm{~S}_{8} @ \mathrm{NC}-6$ sample, the sharp and strong Raman shifts below $750 \mathrm{~cm}^{-1}$ are attributed to Co-Co stretching mode, indicating the presence of a large amount of metallic cobalt [36]. The porous structure feature of the $\mathrm{Co}_{9} \mathrm{~S}_{8} @ \mathrm{NC}$ composites was verified by the nitrogen adsorption-desorption measurement, as shown in Fig. S3a. The isotherms exhibit typical type-IV characteristics, implying a rich existence of mesopores in the $\mathrm{Co}_{9} \mathrm{~S}_{8} @ \mathrm{NC}$ samples. Correspondingly, the Brunauer-Emmett-Teller surface areas for $\mathrm{Co}_{9} \mathrm{~S}_{8} @ \mathrm{NC}-6, \mathrm{Co}_{9} \mathrm{~S}_{8} @ \mathrm{NC}-9$, and $\mathrm{Co}_{9} \mathrm{~S}_{8} @ \mathrm{NC}-12$ were calculated to be $62.3,42.1$, and $19.6 \mathrm{~m}^{2} \mathrm{~g}^{-1}$, respectively, which are higher than that of $\mathrm{Co}_{9} \mathrm{~S}_{8}$-NPs $\left(15.1 \mathrm{~m}^{2} \mathrm{~g}^{-1}\right)$. The average pore size of the $\mathrm{Co}_{9} \mathrm{~S}_{8} @ \mathrm{NC}-9$ sample (Fig. S3b) shows the pore size is primarily distributed in the range of 2-4 nm. The presence of both micropores and mesopores can form a multichannel structure that facilitates the electrolyte penetration and electron/ion diffusion [37].

Field emission scanning electron microscopy (FESEM) images of the $\mathrm{Co}_{9} \mathrm{~S}_{8} @ \mathrm{NC}$ composites are shown in Fig. S4. A panoramic view of the $\mathrm{Co}_{9} \mathrm{~S}_{8} @ \mathrm{NC}-6$ and $\mathrm{Co}_{9} \mathrm{~S}_{8} @ \mathrm{NC}-9$ 

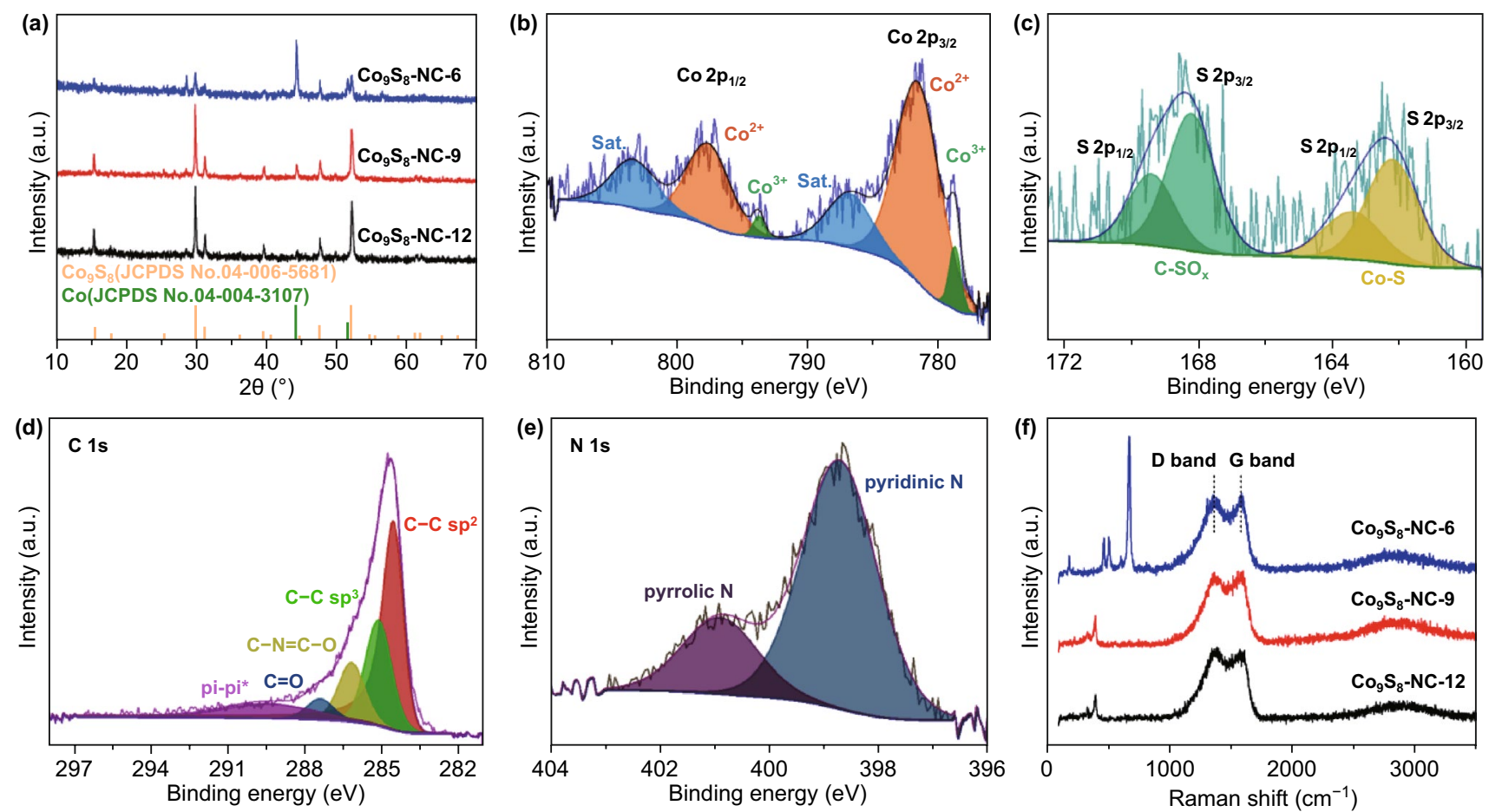

Fig. 1 a XRD pattern of the $\mathrm{Co}_{9} \mathrm{~S}_{8} @ \mathrm{NC}$ composites and the standard XRD patterns of Co (JCPDS No. 04-004-3107) and Co $\mathrm{S}_{8}$ (JCPDS No. 04-006-5681). b-e High-resolution XPS spectra of $\mathrm{Co}_{9} \mathrm{~S}_{8} @ \mathrm{NC}-9$. $\mathbf{f}$ Raman spectra of the $\mathrm{Co}_{9} \mathrm{~S}_{8} @ \mathrm{NC}$

shows the high yield of quasi-spherical NPs with a uniform size of about $100 \mathrm{~nm}$, whereas the $\mathrm{Co}_{9} \mathrm{~S}_{8} @ \mathrm{NC}-12$ sample exhibits irregular shapes. The transmission electron microscopy (TEM) images (Figs. 2a, b and S5) further demonstrate that the $\mathrm{Co}_{9} \mathrm{~S}_{8} @ \mathrm{NC}-9$ exhibits the most intact core-shell structure with $\mathrm{Co}_{9} \mathrm{~S}_{8}$ core NPs encapsulated and linked together by carbon sheets. A close observation (Fig. 2c) indicates the carbon shell consists of $\sim 10-20$ carbon layers that have a welldefined graphite crystalline structure. High-resolution TEM (HRTEM) image (Fig. 2d) evidences the good crystallisation of $\mathrm{Co}_{9} \mathrm{~S}_{8}$ core. The continuous lattice fringe of $\sim 0.227 \mathrm{~nm}$ corresponds to the (331) facet of cubic $\mathrm{Co}_{9} \mathrm{~S}_{8}$, which is in line with the selected area electron diffraction (SAED) pattern results. Moreover, a small amount of ultrafine Co NPs (marked in circles) with $\sim 2-5 \mathrm{~nm}$ in size can be observed, as shown in Fig. 2e, the presence of which has been demonstrated to increase the electronic conductivity of the composite by creating heterointerfaces and promote the formation of robust graphitic carbon [4, 38]. In addition, TEM elemental mapping analysis confirms the even distribution of $\mathrm{Co}, \mathrm{C}, \mathrm{S}$, and $\mathrm{N}$ as the principal elemental components throughout the $\mathrm{Co}_{9} \mathrm{~S}_{8} @$ NC-9 sample, consistent with the full survey XPS spectrum result above. Such structure design offers multiple merits for achieving excellent sodium-ion storage. The direct, intimate contact between the core $\mathrm{Co}_{9} \mathrm{~S}_{8}$ NPs and thin carbon shells provides efficient electron/ion transport media, which contribute to the excellent rate capability. The space-confined effect arising from the carbon capsules can impede the growth and aggregation of the core $\mathrm{Co}_{9} \mathrm{~S}_{8}$ NPs while buffering the volume change upon the electrochemical reaction, which ensures a stable SEI film and alleviates the capacity fading against extended cycling.

\subsection{Sodium-Ion Storage Performance in Half Cells}

To evaluate the $\mathrm{Co}_{9} \mathrm{~S}_{8} @ \mathrm{NC}$ as anode for NIBs, the electrochemical performance was tested in coin-type half cells. Figures 3a and S6a, b show the CV curves of $\mathrm{Co}_{9} \mathrm{~S}_{8} @ \mathrm{NC}$ electrodes for the initial three cycles. In the $\mathrm{CV}$ profile of $\mathrm{Co}_{9} \mathrm{~S}_{8} @$ NC-9, the initial reduction process shows peaks between 0.15 and $1.0 \mathrm{~V}$, which corresponds to the sodiation of both carbon and $\mathrm{Co}_{9} \mathrm{~S}_{8}$, along with the decomposition of electrolyte and the formation of the SEI layer. In particular, the peak located at $0.9 \mathrm{~V}$ corresponds to the interaction of $\mathrm{Co}_{9} \mathrm{~S}_{8}$ with sodium 

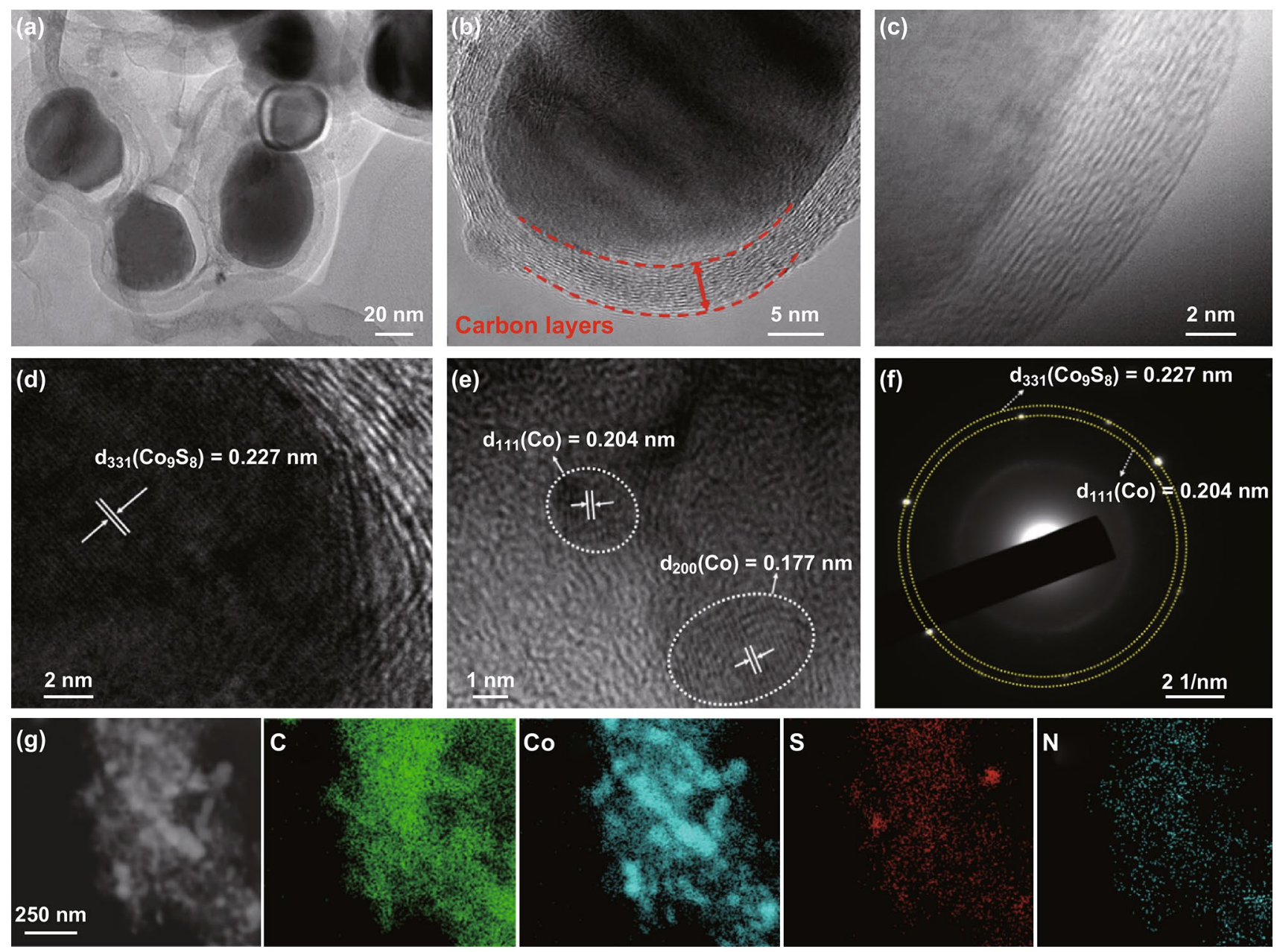

Fig. 2 Morphology and structure of the as-prepared $\mathrm{Co}_{9} \mathrm{~S}_{8} @ \mathrm{NC}-9$. a-c TEM images with different magnifications. d, e HRTEM images presenting the lattice fringes. $\mathbf{f}$ SAED pattern. $\mathbf{g}$ Elemental mapping images showing the distribution of $\mathrm{C}, \mathrm{Co}, \mathrm{S}$, and $\mathrm{N}$ elements

ions to form a $\mathrm{Na}_{2-x} \mathrm{Co}_{9} \mathrm{~S}_{8}$ phase, while the peak at $0.55 \mathrm{~V}$ is related to $\mathrm{Na}_{2-x} \mathrm{Co}_{9} \mathrm{~S}_{8}$ transforming to $\mathrm{Co}$ and $\mathrm{Na}_{2} \mathrm{~S}$ via conversion reaction [4], which will be illustrated later by TEM and in situ XRD results. In the subsequent cycles, the new cathodic peak at 0.95 evolved instead, which are related to the reaction between $\mathrm{Na}_{2-x} \mathrm{Co}_{9} \mathrm{~S}_{8}$ and sodium ions. During the anodic scan, the oxidation peak located at $1.67 \mathrm{~V}$ is due to the desodiation process. Moreover, there are a pair of reversible peaks located at $\sim 0.1 \mathrm{~V}$ for both cathodic and anodic scans, which are due to the intercalation/deintercalation of solvated sodium ions into/from nano-voids formed by the disordered carbon nanosheets [39].

Accordingly, the galvanostatic discharge-charge profiles of $\mathrm{Co}_{9} \mathrm{~S}_{8} @ \mathrm{NC}$ electrodes are shown in Figs. 3b and S6c, d. The long discharge plateau in the first cycle is related to the sodiation process and SEI formation, accordant with the CV profiles. The initial discharge/charge capacities of $\mathrm{Co}_{9} \mathrm{~S}_{8} @$ NC-6, $\mathrm{Co}_{9} \mathrm{~S}_{8} @ \mathrm{NC}-9$, and $\mathrm{Co}_{9} \mathrm{~S}_{8} @ \mathrm{NC}-12$ electrodes were $568 / 430,1034 / 709$, and $807 / 601 \mathrm{mAh} \mathrm{g}^{-1}$ at $100 \mathrm{~mA} \mathrm{~g}^{-1}$, respectively. The first irreversible capacity is attributed to the partial reductive decomposition of the electrolyte and the SEI formation. The overlapping of the discharge-charge profiles as well as the CV curves after the first cycle of the $\mathrm{Co}_{9} \mathrm{~S}_{8}$ @ NC-9 is an indication of the highly reversible reaction of the electrode materials with sodium ions. In addition, it should be noticed that excessive carbon content in the $\mathrm{Co}_{9} \mathrm{~S}_{8} @ \mathrm{NC}-6$ sample led to inferior performance, which might stem from the low capacity of carbon.

Impressively, the $\mathrm{Co}_{9} \mathrm{~S}_{8} @ \mathrm{NC}-9$ electrode shows an extraordinary rate performance by achieving capacities of 705 , 
$701,675,652,645,629$, and $613 \mathrm{mAh} \mathrm{g}^{-1}$ at current densities of 100, 200, 400, 800, 1000, 2000, and $4000 \mathrm{~mA} \mathrm{~g}^{-1}$, respectively, as shown in Fig. $3 \mathrm{c}$ and d, which are better than $\mathrm{Co}_{9} \mathrm{~S}_{8} @ \mathrm{NC}-6, \mathrm{Co}_{9} \mathrm{~S}_{8} @ \mathrm{NC}-12$, and $\mathrm{Co}_{9} \mathrm{~S}_{8}$-NP electrodes (Figs. 3c and S6e, f). Importantly, after successive 43 cycles at different current densities, the capacity of $\mathrm{Co}_{9} \mathrm{~S}_{8} @ \mathrm{NC}-9$
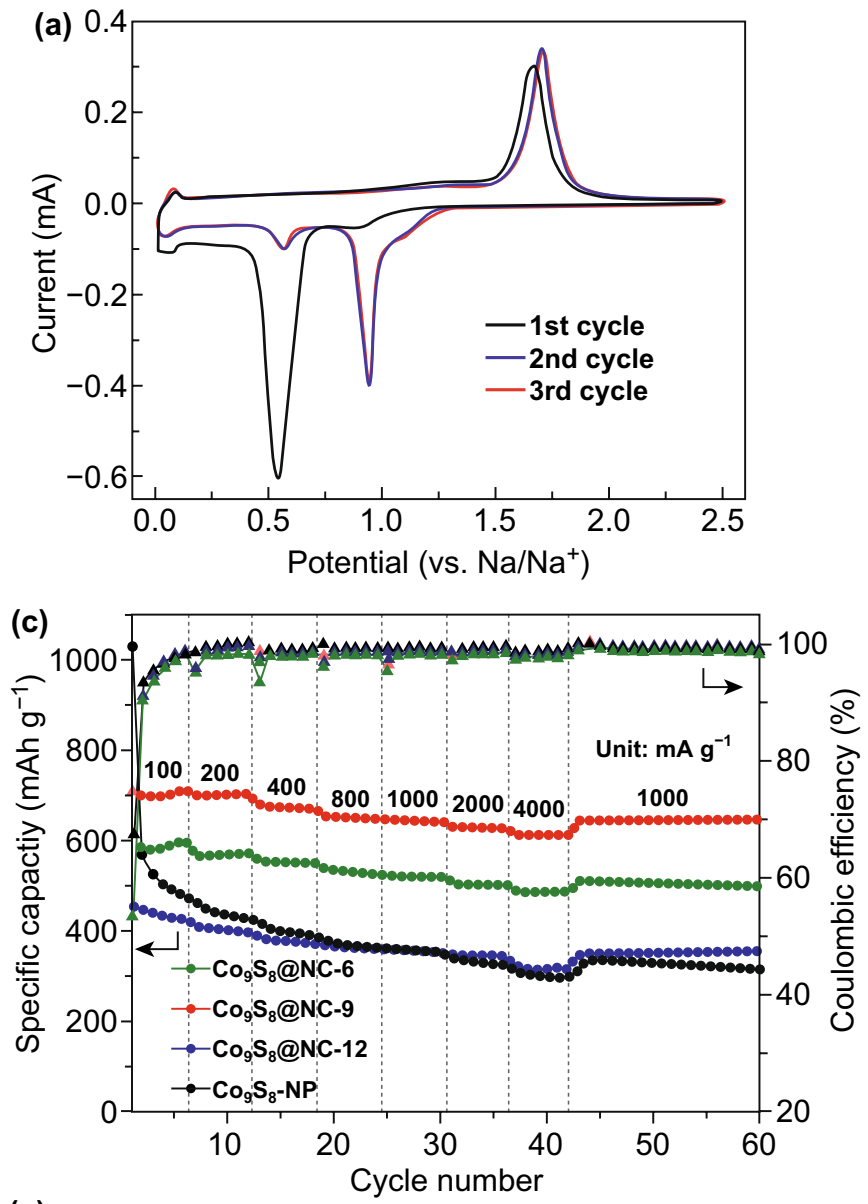

was retained to $645 \mathrm{mAh} \mathrm{g}^{-1}$ when the current density was changed to $1000 \mathrm{~mA} \mathrm{~g}^{-1}$. The excellent rate performance of $\mathrm{Co}_{9} \mathrm{~S}_{8} @ \mathrm{NC}-9$ was attributed to the fast charge transport kinetics throughout the electrode, likely due to both material integrity against the volumetric expansion as well as the high electron conductivity from the rational-designed structure with
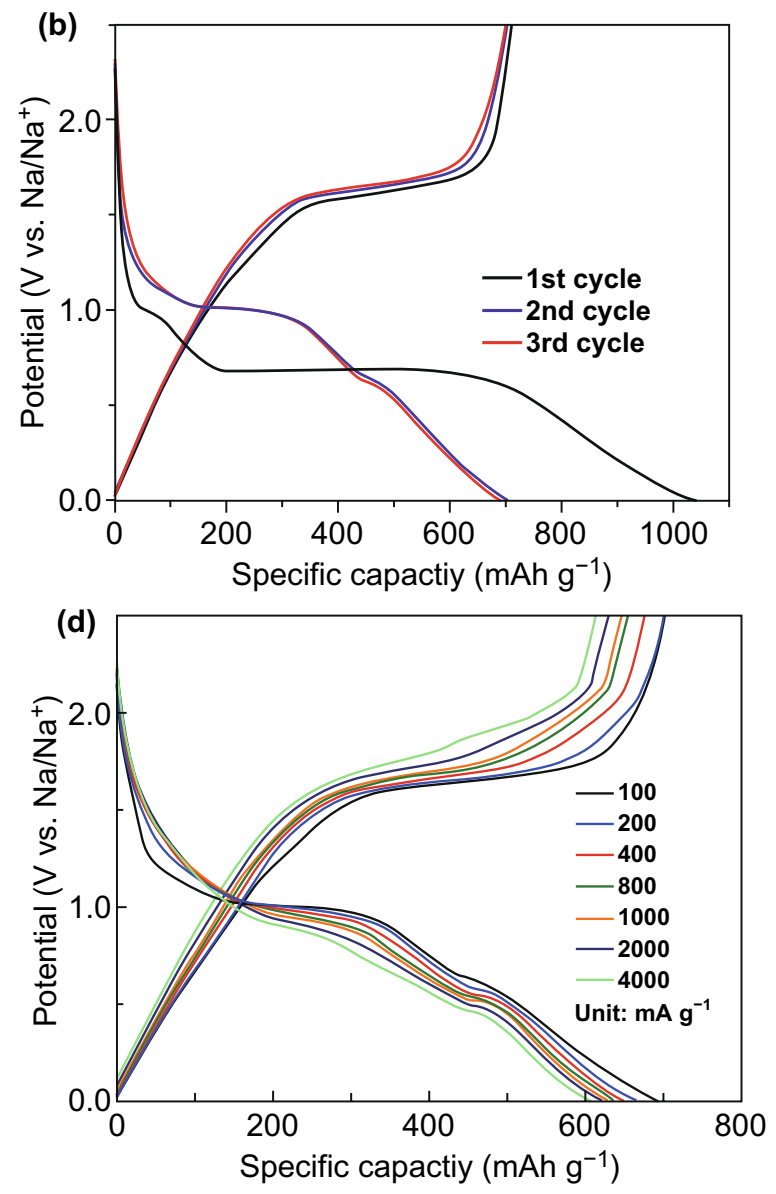

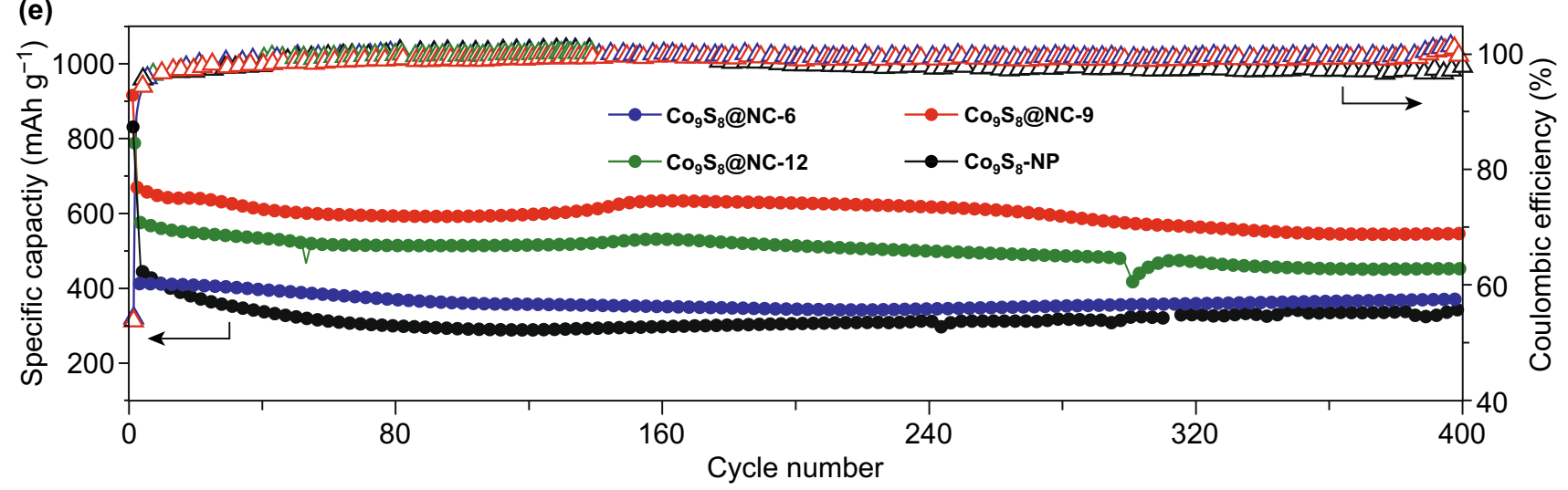

Fig. 3 Electrochemical performance of the $\mathrm{Co}_{9} \mathrm{~S}_{8} @ \mathrm{NC}$ electrodes. a CV profiles of $\mathrm{Co}_{9} \mathrm{~S}_{8} @ \mathrm{NC}-9$ electrode for the initial three cycles. b Galvanostatic discharge-charge profiles of $\mathrm{Co}_{9} \mathrm{~S}_{8} @ \mathrm{NC}-9$ at $100 \mathrm{~mA} \mathrm{~g}{ }^{-1}$. $\mathbf{c}$ Rate performance and corresponding d discharge-charge profiles at various current densities from 100 to $4000 \mathrm{~mA} \mathrm{~g}^{-1}$. e Long-term cycling stability at a high current density of $1000 \mathrm{~mA} \mathrm{~g}^{-1}$ 

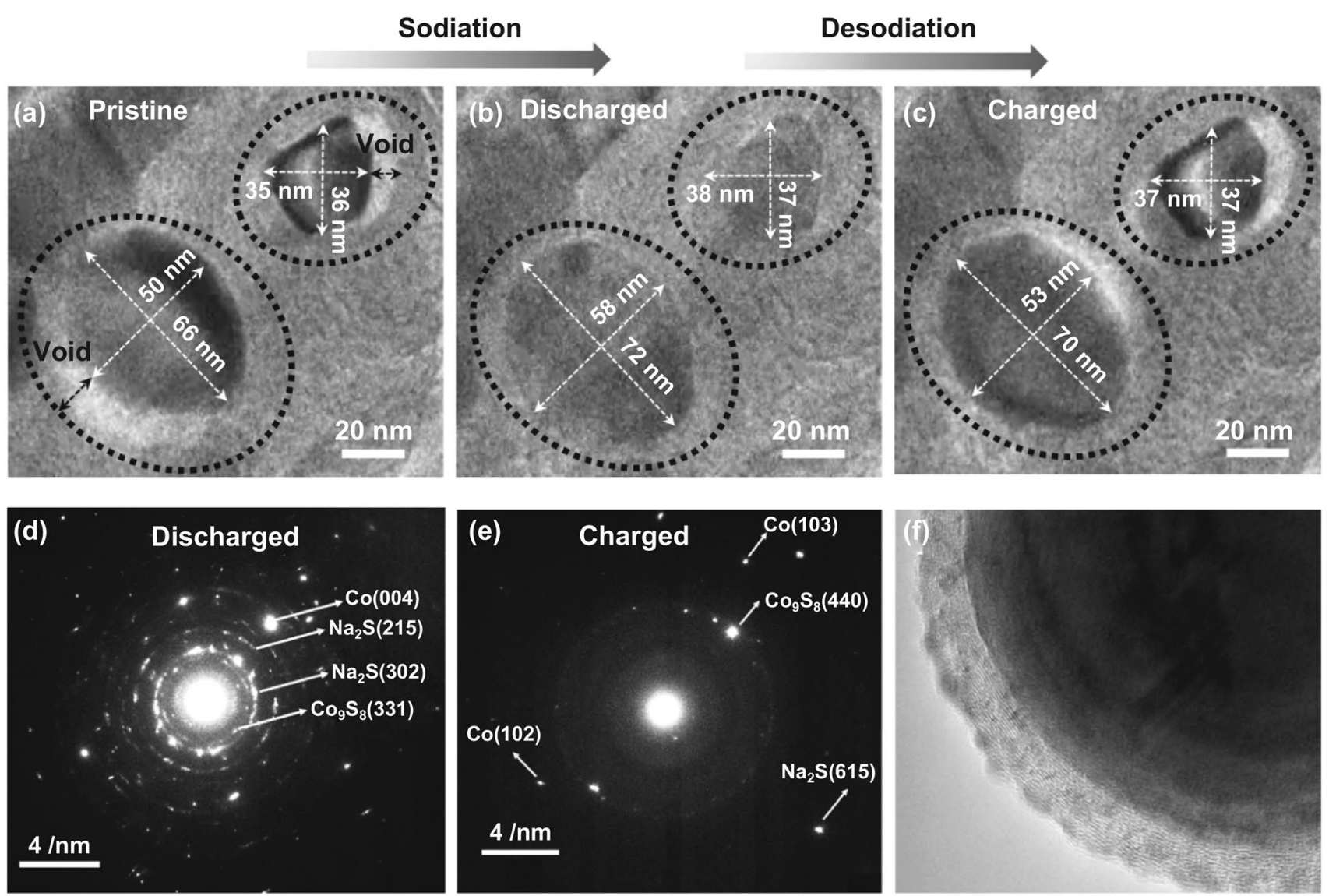

Fig. 4 a-c In situ TEM investigation of structural changes of the $\mathrm{Co}_{9} \mathrm{~S}_{8} @ \mathrm{NC}$ electrode during varied sodiation depths. SAED patterns the $\mathrm{Co}_{9} \mathrm{~S}_{8} @ \mathrm{NC}$ electrode at $\mathbf{d}$ sodiated to $0.01 \mathrm{~V}$ and e desodiated to $2.5 \mathrm{~V}$ illustrating the compositional changes. f HRTEM images of Co $\mathrm{S}_{8} @ \mathrm{NC}$ electrode after long-term cycling after 400 cycles

multi-functional electrochemical active components. Moreover, the cycling performance of the $\mathrm{Co}_{9} \mathrm{~S}_{8} @ \mathrm{NC}-6, \mathrm{Co}_{9} \mathrm{~S}_{8} @$ $\mathrm{NC}-9, \mathrm{Co}_{9} \mathrm{~S}_{8} @ \mathrm{NC}-12$, and $\mathrm{Co}_{9} \mathrm{~S}_{8}-\mathrm{NP}$ electrodes were investigated, as shown in Fig. 3e. The $\mathrm{Co}_{9} \mathrm{~S}_{8} @ \mathrm{NC}-9$ electrode shows no virtually capacity fading at a high rate of $1000 \mathrm{~mA} \mathrm{~g}^{-1}$ over 400 cycles with a high Coulombic efficiency of $\sim 99.8 \%$, indicating a high reversible reaction with sodium ions and the structural stability of the electrode material. The retained capacity of $\mathrm{Co}_{9} \mathrm{~S}_{8} @ \mathrm{NC}-6, \mathrm{Co}_{9} \mathrm{~S}_{8} @ \mathrm{NC}-9, \mathrm{Co}_{9} \mathrm{~S}_{8} @ \mathrm{NC}-12$, and $\mathrm{Co}_{9} \mathrm{~S}_{8}$-NP electrodes after 500 cycles were 556, 458, 374, and $331 \mathrm{mAh} \mathrm{g}^{-1}$, corresponding to the capacity retention of $82,78,81$, and $69 \%$, respectively. It is noted that the $\mathrm{Co}_{9} \mathrm{~S}_{8} @$ $\mathrm{NC}$ electrodes exhibit better cycling performance and rate capability than that of the $\mathrm{Co}_{9} \mathrm{~S}_{8}$-NP electrode, which could be attributed to the introduction of carbon encapsulation as well as the nitrogen doping. It can also be concluded that the $\mathrm{Co}_{9} \mathrm{~S}_{8} @ \mathrm{NC}-9$ electrode with an intact core-shell structure, hierarchical pores on the carbon layers and a relatively large surface area is the optimised choice in this work by providing high capacity, excellent rate capability and good stability against long-term cycling.

\subsection{Sodium-Driven Structural and Compositional Changes}

To understand the structural merits of the $\mathrm{Co}_{9} \mathrm{~S}_{8} @ \mathrm{NC}-9$ associated with this fast and highly stable reaction, in situ and ex situ TEM techniques were performed to optically probe the composition and structure of the $\mathrm{Co}_{9} \mathrm{~S}_{8} @ \mathrm{NC}-9$ electrode during electrochemical testing. The volume changes of the $\mathrm{Co}_{9} \mathrm{~S}_{8} @$ NC-9 due to sodiation/desodiation were captured of the initial, sodiated and desodiated stages, shown in Fig. 4a-c. In pristine electrode, a core-shell structure with a hollow interior between the $\mathrm{Co}_{9} \mathrm{~S}_{8}$ core and the carbon shell (in white circles, Fig. 4a) can be observed. During the consecutive sodiation, the interior 
voids were gradually filled by the expanded $\mathrm{Co}_{9} \mathrm{~S}_{8}$ core, clearly illustrating that the $\mathrm{Co}_{9} \mathrm{~S}_{8}$ electrode material expanded upon sodiation and ultimately confined by the carbon shells. To measure the volume expansion, two core $\mathrm{Co}_{9} \mathrm{~S}_{8}$ NPs with diameters of $\approx 50 \mathrm{~nm}$ in width and $\approx 66 \mathrm{~nm}$ in length, and $\approx 35 \mathrm{~nm}$ in width and $\approx 36 \mathrm{~nm}$ in length, respectively, were selected as indicated by the prominent markers and arrows. After sodiation, the two positioning arrows placed at the markers expanded to $\approx 58$ and $72 \mathrm{~nm}$ for the large $\mathrm{NP}$ and to $\approx 38$ and $37 \mathrm{~nm}$ for the small $\mathrm{NP}$, respectively, giving a volume expansion of $\approx 46$ and $21 \%$, respectively. These values are much smaller than the observed volume expansion in a previous study, i.e., $120.8 \%$ expansion of $\mathrm{Co}_{9} \mathrm{~S}_{8}$ upon sodiation [7], due to the confinement effect from the graphitic carbon layers. Moreover, the sodiated $\mathrm{Co}_{9} \mathrm{~S}_{8} @ \mathrm{NC}-9$ presented neither fracture of carbon layers nor degradation of $\mathrm{Co}_{9} \mathrm{~S}_{8} \mathrm{NPs}$, indicating the successful confinement of $\mathrm{Co}_{9} \mathrm{~S}_{8}$ NPs by the mechanically robust carbon layers. Figure S7 shows ex situ HRTEM image of the sodiated electrode, displaying plenty of nanograins of about $5-10 \mathrm{~nm}$ in size. The SAED pattern of the sodiated region (Fig. 4d) confirms the formation of $\mathrm{Na}_{2} \mathrm{~S}$ and $\mathrm{Co}$ as conversion products. After desodiation, the volume of $\mathrm{Co}_{9} \mathrm{~S}_{8}$ NPs returned to a slight expansion of 19 and $15 \%$, respectively. The SAED pattern demonstrates that the conversion products of $\mathrm{Co}$ and $\mathrm{Na}_{2} \mathrm{~S}$ returned to $\mathrm{Co}_{9} \mathrm{~S}_{8}$ with tiny residues, as shown in Fig. 4e. Moreover, Figs. $4 \mathrm{f}$ and S8 show HRTEM images of the long-cycled $\mathrm{Co}_{9} \mathrm{~S}_{8} @ \mathrm{NC}-9$ electrode, verifying that $\mathrm{Co}_{9} \mathrm{~S}_{8}$ NPs were still restricted by carbon shells and carbon layers were well preserved after long-term cycling. The low volume variation, as well as the excellent structural stability of the $\mathrm{Co}_{9} \mathrm{~S}_{8} @ \mathrm{NC}-9$ electrode, provides solid evidence for its excellent cycling performance in real batteries.

The sodium storage mechanism of the $\mathrm{Co}_{9} \mathrm{~S}_{8} @ \mathrm{NC}-9$ electrode was further confirmed by means of operando XRD at various sodiated and desodiated stages of the first cycle (Fig. 5a). The corresponding galvanostatic discharge-charge profile at a current density of $20 \mathrm{~mA} \mathrm{~g}^{-1}$ is shown in Fig. 5 b. During the first discharging, the (311) reflection of $\mathrm{Co}_{9} \mathrm{~S}_{8}$ shifted gradually towards a higher $2 \theta$ degree (smaller $d$-spacing), which is likely due to the reinforced electrostatic attraction between the inserted sodium ions and $\mathrm{Co}_{9} \mathrm{~S}_{8}$ lattice [40]. Subsequently, the (311) peak weakened and eventually vanished after $0.6 \mathrm{~V}$, indicating the ongoing structural transformation from $\mathrm{Na}_{x} \mathrm{Co}_{9} \mathrm{~S}_{8}$ to $\mathrm{Co}$ and $\mathrm{Na}_{2} \mathrm{~S}$. Due to the small nanocrystal size ( $\sim 2-5 \mathrm{~nm}$ shown in TEM images) of

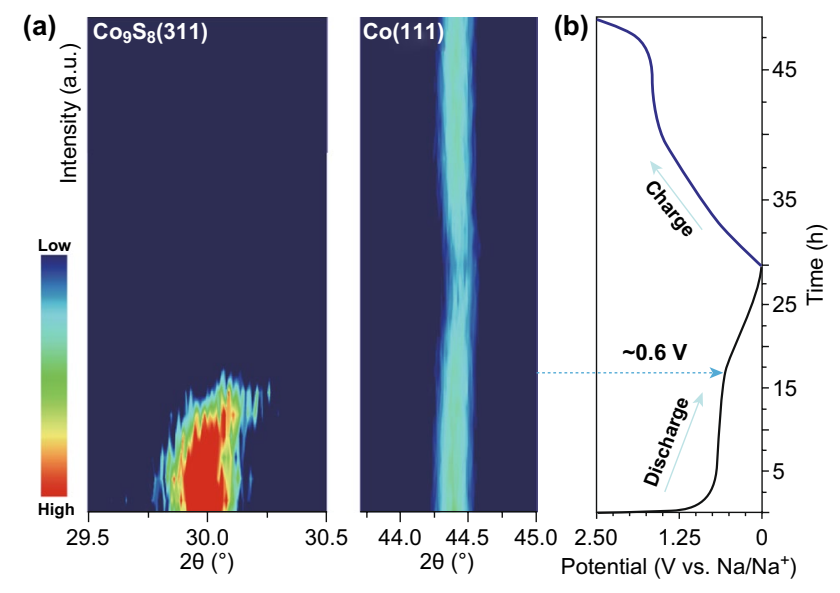

Fig. 5 Operando XRD patterns collected at various states of the initial discharge/charge process of a $\mathrm{Co}_{9} \mathrm{~S}_{8} @ \mathrm{NC}-9 /$ sodium electrochemical cell. Contour plots of the diffraction peak evolution of $\mathrm{Co}_{9} \mathrm{~S}_{8}$ (311) and Co (111) planes. The corresponding galvanostatic discharge-charge profiles at a current density of $20 \mathrm{~mA} \mathrm{~g}^{-1}$ from the open circuit potential to $0.01 \mathrm{~V}$

the conversion products, the reflections of the newly formed $\mathrm{Na}_{2} \mathrm{~S}$ and Co could be broad and become part of the background of the XRD patterns. Meanwhile, a gradual shift of the Co (111) reflection towards a higher angle is observed, indicating a slight lattice contraction during the sodiation process. After sodium ions retrieved from the electrode, the Co (111) peak is fully recovered to its pristine state. The reversible interaction of $\mathrm{Co}_{9} \mathrm{~S}_{8}$ with sodium ions is benefiting from the well-retained structure that restrains the loss of active components during conversion reaction.

\subsection{Electrochemical Performance in a Sodium-Ion Capacitor}

To demonstrate the feasibility of using $\mathrm{Co}_{9} \mathrm{~S}_{8} @ \mathrm{NC}-9$ for high-power energy storage applications, we fabricated a Swagelok-type full cell sodium-ion capacitor (NIC) using the pre-sodiated $\mathrm{Co}_{9} \mathrm{~S}_{8} @ \mathrm{NC}-9$ as the negative electrode, paired with the cellulose-derived porous carbon/graphene oxide composites (CG) as the ion adsorption/desorption positive electrode. The structure characterisation of the $\mathrm{CG}$ positive electrode is shown in Fig. S9. The CV test of $\mathrm{Co}_{9} \mathrm{~S}_{8} @$ NC-9 and CG electrodes at various scan rates was performed in sodium half cells, as shown in Fig. S10. When assembled for a NIC full cell, the CV curve of the $\mathrm{Co}_{9} \mathrm{~S}_{8} @ \mathrm{NC}-9 / / \mathrm{CG}$ NIC exhibits a typical capacitive charge storage behaviour, 

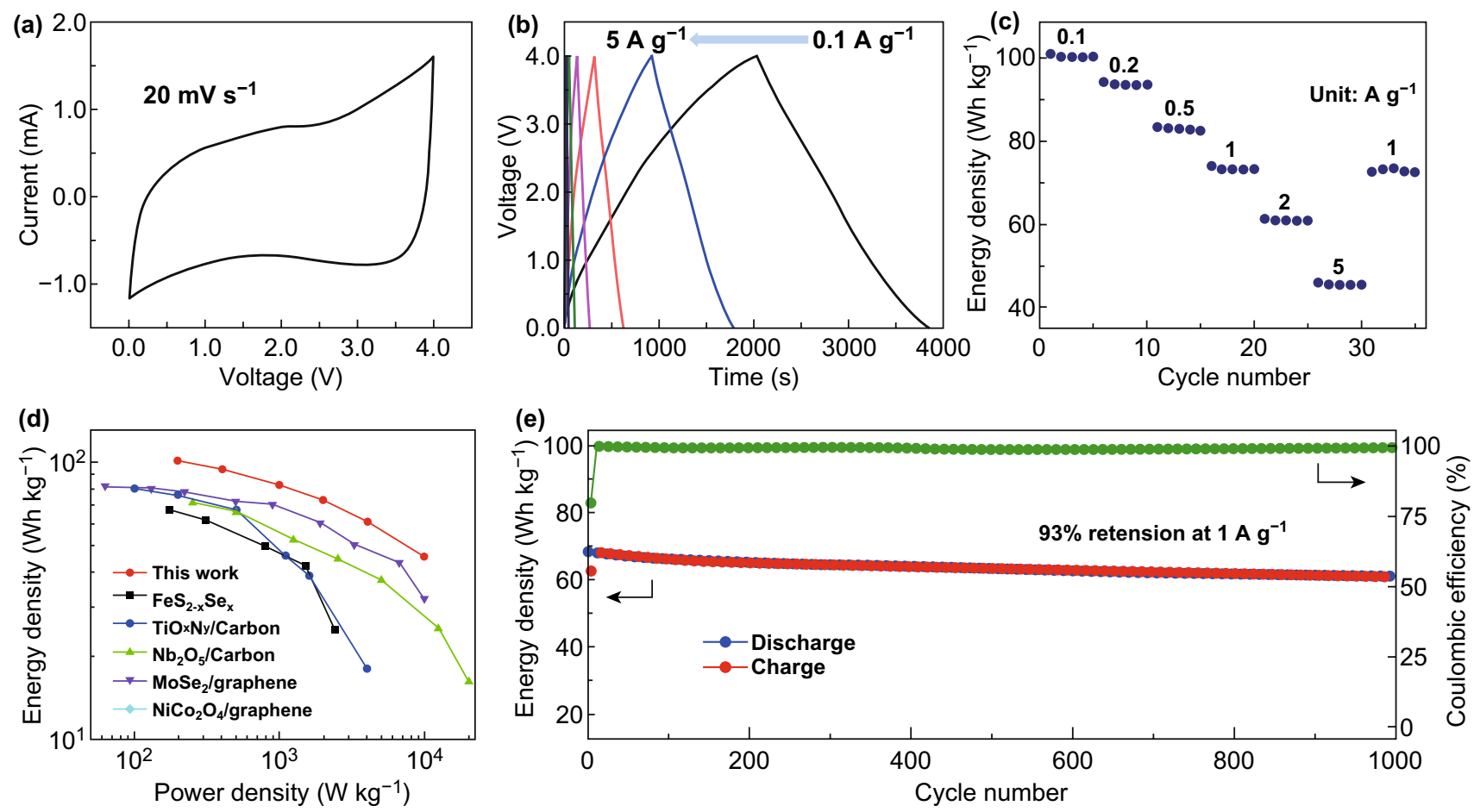

Fig. 6 Electrochemical performance of the $\mathrm{Co}_{9} \mathrm{~S}_{8} @ \mathrm{NC}-9 / / \mathrm{CG}$ NIC cells. a The CV curves of the $\mathrm{Co}_{9} \mathrm{~S}_{8} @ \mathrm{NC}-9 / / \mathrm{CG}$ NIC full cell. b Galvanostatic charge-discharge profiles and $\mathbf{c}$ rate performance at various current densities from 0.1 to $5 \mathrm{~A} \mathrm{~g}^{-1}$. $\mathbf{d}$ Ragone plots of the Co $9 \mathrm{~S}_{8} @ \mathrm{NC}-9 / / \mathrm{CG}$ NIC cell and the comparison with other reported NIC systems. e Cycling performance of $\mathrm{Co}_{9} \mathrm{~S}_{8} @ \mathrm{NC}-9 / / \mathrm{CG}$ NIC at a rate of 1 A g ${ }^{-1}$

as shown in Fig. 6a, indicating that $\mathrm{Co}_{9} \mathrm{~S}_{8} @ \mathrm{NC}-9$ electrode could be a suitable anode for NICs. Figure $6 \mathrm{~b}$ shows the galvanostatic charge-discharge profiles of the $\mathrm{Co}_{9} \mathrm{~S}_{8} @ \mathrm{NC} / /$ CG NIC at various current densities from 0.1 to $5 \mathrm{~A} \mathrm{~g}^{-1}$. The nearly linear profiles at various current rates are indicative of the fast charge storage kinetics. As shown in the Ragone plots of NIC full cells in Fig. 6d, the as-assembled NIC delivered a superior energy density of $101.4 \mathrm{Wh} \mathrm{kg}^{-1}$ at a power density of $\sim 200 \mathrm{~W} \mathrm{~kg}^{-1}$ and maintained an energy density of $45.8 \mathrm{Wh} \mathrm{kg}^{-1}$ at a high power density of $\sim 10,000 \mathrm{~W} \mathrm{~kg}^{-1}$, demonstrating an extraordinary high rate characteristic. When compared with various recently reported high-performance NICs [41-44], the $\mathrm{Co}_{9} \mathrm{~S}_{8} @$ NC-9//CG NIC device shows superior high energy and high power performance. Moreover, the NIC shows a high capacity retention of $93 \%$ and high Coulombic efficiency of about 99.9\% over 1000 cycles at $1 \mathrm{~A} \mathrm{~g}^{-1}$ (Fig. 6e), manifesting the advantages of hybrid devices with both highly reversible sodium-ion storage capability and good cycling stability. The above results indicate that the as-designed $\mathrm{Co}_{9} \mathrm{~S}_{8} @ \mathrm{NC}$ electrode with a unique structure would open the avenue to advanced high-performance NICs.

\section{Conclusions}

Herein, we report a high electrochemical performance composite anode with cobalt sulphide nanoparticles encapsulated by a spherical carbon shell with nitrogen doping for sodium-ion storage. The high conductivity of carbon and the core-shell-like structure of the electrode material contributed to the enhancement in the electrochemical properties of the composite electrode in a synergistic manner. In-depth investigation using in situ TEM confirmed the effect of carbon buffering the volume change. Further, the carbon shell was well preserved after repeated cycling. High capacity and shelf-life along with scalability make the present material attractive as next-generation sodium-ion battery anode material. This work could be translated to other transition metal chalcogenides using such material design to realise inexpensive and durable electrode materials for practical application in batteries. 
Acknowledgements This work was supported by The Australian Research Council (ARC) under project FL170100101. YW wishes to thank The University of Queensland for offering UQI Scholarship. The authors acknowledge the facilities, and the scientific and technical assistance, of the Australian Microscopy and Microanalysis Research Facility at The Centre for Microscopy and Microanalysis, The University of Queensland.

Open Access This article is licensed under a Creative Commons Attribution 4.0 International License, which permits use, sharing, adaptation, distribution and reproduction in any medium or format, as long as you give appropriate credit to the original author(s) and the source, provide a link to the Creative Commons licence, and indicate if changes were made. The images or other third party material in this article are included in the article's Creative Commons licence, unless indicated otherwise in a credit line to the material. If material is not included in the article's Creative Commons licence and your intended use is not permitted by statutory regulation or exceeds the permitted use, you will need to obtain permission directly from the copyright holder. To view a copy of this licence, visit http://creativecommons.org/licenses/by/4.0/.

Electronic supplementary material The online version of this article (https://doi.org/10.1007/s40820-020-0391-9) contains supplementary material, which is available to authorized users.

\section{References}

1. Y. Xiao, S.H. Lee, Y.-K. Sun, The application of metal sulfides in sodium ion batteries. Adv. Energy Mater. 7(3), 1601329 (2017). https://doi.org/10.1002/aenm.201601329

2. Q. Zhou, L. Liu, G. Guo, Z. Yan, J. Tan, Z. Huang, X. Chen, X. Wang, Sandwich-like cobalt sulfide-graphene composite-an anode material with excellent electrochemical performance for sodium ion batteries. RSC Adv. 5(88), 71644-71651 (2015). https://doi.org/10.1039/C5RA12478F

3. R. Thangavel, A. Samuthira Pandian, H.V. Ramasamy, Y.-S. Lee, Rapidly synthesized, few-layered pseudocapacitive $\mathrm{SnS}_{2}$ anode for high-power sodium ion batteries. ACS Appl. Mater. Interfaces 9(46), 40187-40196 (2017). https://doi. org/10.1021/acsami.7b11040

4. Y. Zhao, Q. Pang, Y. Wei, L. Wei, Y. Ju, B. Zou, Y. Gao, G. Chen, $\mathrm{Co}_{9} \mathrm{~S}_{8} / \mathrm{Co}$ as a high-performance anode for sodiumion batteries with an ether-based electrolyte. Chemsuschem 10(23), 4778-4785 (2017). https://doi.org/10.1002/cssc.20170 1334

5. Y. Wang, Y. Wang, Y.-X. Wang, X. Feng, W. Chen et al., In situ formation of $\mathrm{Co}_{9} \mathrm{~S}_{8}$ nanoclusters in sulfur-doped carbon foam as a sustainable and high-rate sodium-ion anode. ACS Appl. Mater. Interfaces 11(21), 19218-19226 (2019). https://doi.org/10.1021/acsami.9b05134

6. C. Guo, W. Zhang, Y. Liu, J. He, S. Yang, M. Liu, Q. Wang, $\mathrm{Z}$. Guo, Constructing $\mathrm{CoO} / \mathrm{Co}_{3} \mathrm{~S}_{4}$ heterostructures embedded in $\mathrm{N}$-doped carbon frameworks for high-performance sodium-ion batteries. Adv. Funct. Mater. 29(29), 1901925 (2019). https://doi.org/10.1002/adfm.201901925

7. Q. Su, G. Du, J. Zhang, Y. Zhong, B. Xu, Y. Yang, S. Neupane, W. Li, In situ transmission electron microscopy observation of electrochemical sodiation of individual $\mathrm{Co}_{9} \mathrm{~S}_{8}$-filled carbon nanotubes. ACS Nano 8(4), 3620-3627 (2014). https://doi.org/10.1021/nn500194q

8. M.Á. Muñoz-Márquez, D. Saurel, J.L. Gómez-Cámer, M. Casas-Cabanas, E. Castillo-Martínez, T. Rojo, Na-ion batteries for large scale applications: a review on anode materials and solid electrolyte interphase formation. Adv. Energy Mater. 7(20), 1700463 (2017). https://doi.org/10.1002/ aenm.201700463

9. M. Walter, T. Zünd, M.V. Kovalenko, Pyrite $\left(\mathrm{FeS}_{2}\right)$ nanocrystals as inexpensive high-performance lithium-ion cathode and sodium-ion anode materials. Nanoscale 7(20), 9158-9163 (2015). https://doi.org/10.1039/C5NR00398A

10. X. Xie, Z. Ao, D. Su, J. Zhang, G. Wang, $\mathrm{MoS}_{2} /$ graphene composite anodes with enhanced performance for sodiumion batteries: the role of the two-dimensional heterointerface. Adv. Funct. Mater. 25(9), 1393-1403 (2015). https://doi. org/10.1002/adfm.201404078

11. J. Bai, B. Xi, H. Mao, Y. Lin, X. Ma, J. Feng, S. Xiong, Onestep construction of N, P-codoped porous carbon sheets/ CoP hybrids with enhanced lithium and potassium storage. Adv. Mater. 30(35), 1802310 (2018). https://doi.org/10.1002/ adma.201802310

12. T. Wang, H.C. Chen, F. Yu, X.S. Zhao, H. Wang, Boosting the cycling stability of transition metal compounds-based supercapacitors. Energy Storage Mater. 16, 545-573 (2019). https ://doi.org/10.1016/j.ensm.2018.09.007

13. F. Yu, Z. Chang, X. Yuan, F. Wang, Y. Zhu et al., Ultrathin $\mathrm{NiCo}_{2} \mathrm{~S}_{4} @$ graphene with a core-shell structure as a high performance positive electrode for hybrid supercapacitors. J. Mater. Chem. A 6(14), 5856-5861 (2018). https://doi. org/10.1039/C8TA00835C

14. F. Yao, F. Güneş, H.Q. Ta, S.M. Lee, S.J. Chae et al., Diffusion mechanism of lithium ion through basal plane of layered graphene. J. Am. Chem. Soc. 134(20), 8646-8654 (2012). https ://doi.org/10.1021/ja301586m

15. A.L.M. Reddy, A. Srivastava, S.R. Gowda, H. Gullapalli, M. Dubey, P.M. Ajayan, Synthesis of nitrogen-doped graphene films for lithium battery application. ACS Nano 4(11), 63376342 (2010). https://doi.org/10.1021/nn101926g

16. W. Yang, J. Zhou, S. Wang, W. Zhang, Z. Wang, F. Lv, K. Wang, Q. Sun, S. Guo, Freestanding film made by necklacelike $\mathrm{N}$-doped hollow carbon with hierarchical pores for highperformance potassium-ion storage. Energy Environ. Sci. 12(5), 1605-1612 (2019). https://doi.org/10.1039/C9EE0 $0536 \mathrm{~F}$

17. X. Xu, H. Zeng, D. Han, K. Qiao, W. Xing, M.J. Rood, Z. Yan, Nitrogen and sulfur co-doped graphene nanosheets to improve anode materials for sodium-ion batteries. ACS Appl. Mater. Interfaces 10(43), 37172-37180 (2018). https://doi. org/10.1021/acsami.8b15940 
18. R.R. Gaddam, A.H. Farokh Niaei, M. Hankel, D.J. Searles, N.A. Kumar, X.S. Zhao, Capacitance-enhanced sodium-ion storage in nitrogen-rich hard carbon. J. Mater. Chem. A 5(42), 22186-22192 (2017). https://doi.org/10.1039/C7TA06754B

19. T. Zhang, H. Qu, K. Sun, S. Li, Facile fabrication of $\mathrm{Co}_{9} \mathrm{~S}_{8}$ embedded in a boron and nitrogen co-doped carbon matrix as sodium-ion battery anode. ChemElectroChem 6(6), 17761783 (2019). https://doi.org/10.1002/celc.201801843

20. M. Yin, X. Feng, D. Zhao, Y. Zhao, H. Li et al., Hierarchical $\mathrm{Co}_{9} \mathrm{~S}_{8} @$ carbon hollow microspheres as an anode for sodium ion batteries with ultralong cycling stability. ACS Sustain. Chem. Engin. 7(6), 6122-6130 (2019). https://doi. org/10.1021/acssuschemeng.8b06345

21. Y. Zhang, N. Wang, P. Xue, Y. Liu, B. Tang, Z. Bai, S. Dou, $\mathrm{Co}_{9} \mathrm{~S}_{8} @$ carbon nanospheres as high-performance anodes for sodium ion battery. Chem. Engineer. J. 343, 512-519 (2018). https://doi.org/10.1016/j.cej.2018.03.048

22. X. Liu, H. Liu, Y. Zhao, Y. Dong, Q. Fan, Q. Kuang, Synthesis of the carbon-coated nanoparticle $\mathrm{Co}_{9} \mathrm{~S}_{8}$ and its electrochemical performance as an anode material for sodium-ion batteries. Langmuir 32(48), 12593-12602 (2016). https://doi. org/10.1021/acs.langmuir.6b02870

23. L.-L. Feng, G.-D. Li, Y. Liu, Y. Wu, H. Chen, Y. Wang, Y.-C. Zou, D. Wang, X. Zou, Carbon-armored $\mathrm{Co}_{9} \mathrm{~S}_{8}$ nanoparticles as all-ph efficient and durable h2-evolving electrocatalysts. ACS Appl. Mater. Interfaces 7(1), 980-988 (2015). https:// doi.org/10.1021/am507811a

24. X. Sun, H. Lu, P. Liu, T.E. Rufford, R.R. Gaddam, X. Fan, $\mathrm{X}$. Zhao, A reduced graphene oxide-NiO composite electrode with a high and stable capacitance. Sustain. Energy Fuels 2(3), 673-678 (2018). https://doi.org/10.1039/C7SE00420F

25. S. Park, R.S. Ruoff, Chemical methods for the production of graphenes. Nat. Nanotechn. 4(4), 217 (2009). https://doi. org/10.1038/nnano.2009.58

26. R. Li, Y. Dai, B. Chen, J. Zou, B. Jiang, H. Fu, Nitrogen-doped $\mathrm{Co} / \mathrm{Co}_{9} \mathrm{~S}_{8} /$ partly-graphitized carbon as durable catalysts for oxygen reduction in microbial fuel cells. J. Power Sources 307, 1-10 (2016). https://doi.org/10.1016/j.jpowsour.2015.12.115

27. X. Zhang, S. Liu, Y. Zang, R. Liu, G. Liu et al., Co/Co $\mathrm{Co}_{8} @ \mathrm{~S}$, $\mathrm{N}$-doped porous graphene sheets derived from $\mathrm{S}, \mathrm{N}$ dual organic ligands assembled co-MOFs as superior electrocatalysts for full water splitting in alkaline media. Nano Energy 30, 93-102 (2016). https://doi.org/10.1016/j.nanoen.2016.09.040

28. Z. Chen, R. Wu, M. Liu, H. Wang, H. Xu et al., General synthesis of dual carbon-confined metal sulfides quantum dots toward high-performance anodes for sodium-ion batteries. Adv. Funct. Mater. 27(38), 1702046 (2017). https://doi. org/10.1002/adfm.201702046

29. E. Vijayakumar, S.-H. Kang, K.-S. Ahn, Facile electrochemical synthesis of manganese cobalt sulfide counter electrode for quantum dot-sensitized solar cells. J. Electrochem. Soc. 165(5), F375-F380 (2018). https://doi.org/10.1149/2.12118 05jes

30. H. Li, Z. Li, Z. Wu, M. Sun, S. Han, C. Cai, W. Shen, Y. $\mathrm{Fu}$, Nanocomposites of cobalt sulfide embedded carbon nanotubes with enhanced supercapacitor performance. J.
Electrochem. Soc. 166(6), A1031-A1037 (2019). https://doi. org/10.1149/2.0531906jes

31. L. Tang, R. Ji, X. Li, K.S. Teng, S.P. Lau, Energy-level structure of nitrogen-doped graphene quantum dots. J. Mater. Chem. C 1(32), 4908-4915 (2013). https://doi.org/10.1039/ C3TC30877D

32. X. Wang, C.-G. Liu, D. Neff, P.F. Fulvio, R.T. Mayes et al., Nitrogen-enriched ordered mesoporous carbons through direct pyrolysis in ammonia with enhanced capacitive performance. J. Mater. Chem. A 1(27), 7920-7926 (2013). https://doi. org/10.1039/C3TA11342F

33. S. Huang, Y. Li, Y. Feng, H. An, P. Long, C. Qin, W. Feng, Nitrogen and fluorine co-doped graphene as a high-performance anode material for lithium-ion batteries. J. Mater. Chem. A 3(46), 23095-23105 (2015). https://doi.org/10.1039/ C5TA06012E

34. W. Ai, Z. Luo, J. Jiang, J. Zhu, Z. Du et al., Nitrogen and sulfur codoped graphene: multifunctional electrode materials for high-performance Li-ion batteries and oxygen reduction reaction. Adv. Mater. 26(35), 6186-6192 (2014). https://doi. org/10.1002/adma.201401427

35. J. Mujtaba, H. Sun, G. Huang, Y. Zhao, H. Arandiyan, G. Sun, $\mathrm{S}$. $\mathrm{Xu}, \mathrm{J}$. Zhu, $\mathrm{Co}_{9} \mathrm{~S}_{8}$ nanoparticles encapsulated in nitrogendoped mesoporous carbon networks with improved lithium storage properties. RSC Adv. 6(38), 31775-31781 (2016). https://doi.org/10.1039/C6RA03126A

36. H. Yoon, A. Xu, G.E. Sterbinsky, D.A. Arena, Z. Wang et al., In situ non-aqueous nucleation and growth of next generation rare-earth-free permanent magnets. Phys. Chem. Chem. Phys. 17(2), 1070-1076 (2015). https://doi.org/10.1039/C4CP0 $4451 \mathrm{G}$

37. Y. Wu, M. Gong, M.-C. Lin, C. Yuan, M. Angell et al., 3D graphitic foams derived from chloroaluminate anion intercalation for ultrafast aluminum-ion battery. Adv. Mater. 28(41), 9218-9222 (2016). https://doi.org/10.1002/adma.201602958

38. X.F. Lu, Y. Chen, S. Wang, S. Gao, X.W. Lou, Interfacing manganese oxide and cobalt in porous graphitic carbon polyhedrons boosts oxygen electrocatalysis for $\mathrm{Zn}$-air batteries. Adv. Mater. (2019). https://doi.org/10.1002/adma.201902339

39. J. Zhang, D.-W. Wang, W. Lv, S. Zhang, Q. Liang, D. Zheng, F. Kang, Q.-H. Yang, Achieving superb sodium storage performance on carbon anodes through an ether-derived solid electrolyte interphase. Energy Environ. Sci. 10(1), 370-376 (2017). https://doi.org/10.1039/C6EE03367A

40. H.-S. Kim, J.B. Cook, H. Lin, J.S. Ko, S.H. Tolbert, V. Ozolins, B. Dunn, Oxygen vacancies enhance pseudocapacitive charge storage properties of $\mathrm{MoO}_{3-x}$. Nat. Mater. 16, 454 (2016). https://doi.org/10.1038/nmat4810

41. Y. Long, J. Yang, X. Gao, X. Xu, W. Fan, J. Yang, S. Hou, Y. Qian, Solid-solution anion-enhanced electrochemical performances of metal sulfides/selenides for sodium-ion capacitors: the case of $\mathrm{FeS}_{2-\mathrm{x}} \mathrm{Se}_{\mathrm{x}}$. ACS Appl. Mater. Interfaces 10(13), 10945-10954 (2018). https://doi.org/10.1021/acsami.8b00931

42. H. Chen, C. Dai, Y. Li, R. Zhan, M.-Q. Wang et al., An excellent full sodium-ion capacitor derived from a single Ti-based 
metal-organic framework. J. Mater. Chem. A 6(48), 2486024868 (2018). https://doi.org/10.1039/C8TA09072F

43. X. Zhao, W. Cai, Y. Yang, X. Song, Z. Neale, H.-E. Wang, J. Sui, G. Cao, $\mathrm{MoSe}_{2}$ nanosheets perpendicularly grown on graphene with Mo-C bonding for sodium-ion capacitors. Nano Energy 47, 224-234 (2018). https://doi.org/10.1016/j.nanoe n.2018.03.002
44. Y. Wu, X. Fan, R.R. Gaddam, Q. Zhao, D. Yang, X. Sun, C. Wang, X.S. Zhao, Mesoporous niobium pentoxide/carbon composite electrodes for sodium-ion capacitors. J. Power Sources 408, 82-90 (2018). https://doi.org/10.1016/j.jpows our.2018.10.080 